\title{
Integration of transport networks based in spatial data management: a methodological essay on the metropolitan area of Porto
}

\author{
A. Costa, E. Pacheco \& P. Trocado \\ CEGOT, University of Porto, Portugal
}

\begin{abstract}
Among other explanatory factors for the worsening imbalance in modal split that has occurred in the last three decades in the AMPorto (considered here with nine counties, according to Law No. 44/91) is a weak competitive capacity of networks of collective use particularly road passenger transport. More than a dozen companies operate in an area of $817 \mathrm{~km}^{2}$, providing a disjointed service and therefore extremely punitive to the population.

The Portuguese government is carrying out efforts to gather information from carriers. Still, given the possibilities easily reached by new GIS technologies, we admit that there is a data deficit of integration on a territorial basis, also spread over several institutions, which makes the necessary adjustments difficult, whether the decisions by central government and businesses, or those made by the population.

The reflection proposed addresses issues concerning the governance in transport - the desire for integration and practice of fragmentation of networks. It stimulates, from the possibilities offered by GIS, the results of a punitive governmental modus operandi to the operations of public transport.

The exercise is based on the cross-interpretation between the results obtained with the Normative Ordinance no 32/2009 and what we believe to have been a missed opportunity of a governance exercise in the transport domain.

Keywords: urban transport, integration, information management, governance.
\end{abstract}




\section{1 (De)fragmentation of the network of public transport and modal (im)balance}

Under the National Programme for Spatial Planning Policy (PNPOT - Programa Nacional da Política de Ordenamento de Território), clear objectives were set that predicted the review of " ...institutional design and management of the transport sector in metropolitan areas, by implementing metropolitan transport authorities and improving either the efficiency and coordination of transport policies, or its articulation with policies concerning regional planning and the environment", through the development of " ... sustainable urban transport plans, aiming to enhance the use of public transport and non-motorized mobility as well as to improve air quality, more precisely, in areas of high population density." . In this sense, the purpose of "launching programmes for a physical tariff and logical integration of the passenger transport systems, in the continental territory (...) ensuring accessible information concerning the various modes, particularly on the bigger urban areas, promoting the intermodality" (DGOTDU [1]), consolidates the governmental purposes expressed in Normative Ordinance no 32/2009 [2], forcing public transport operators to carry topological data networks, and others outside of their area of expertise, in a platform to be used by the Institute for Mobility and Land Transport (IMTT - Instituto da Mobilidade e dos Transportes Terrestres) to the transport management and then by the operators and the population.

So, if we look back in order to realize how the network of public transport of AMP was built, the enormous difficulty and - why not say it - the inefficiency of the task demanded on the Normative Ordinance no 32/2009 [2] is easily understood. In fact, the public transport network that is currently known in the AMP is the result of an evolution of small companies, whose formation and expansion is based, in each place and time in their history, on economic and spontaneous logic in response to the emerging demand (Pacheco [3]). On the other hand, for those that authorized this service (IMTT), the difficulty in enforcing the legal diplomas (DG,1945 and DR, 1984 to 2003), ended up making the management task easier, based solely in some principles of competition and territorial coverage. This is how you explain the fact that, still today, the collective transport sector keeps orienting its activity via the Transport Regulations on Automobiles (RTA) of 1948 ordinance 37372 [4] (Normative Order 37272 of $31 / 12 / 1948$ ), which introduces more difficulties in the running of private corporations forced to operate in territorial contexts that, from the competition's point of view; or regarding the size and demand fluctuation, are substantially different from the scenario of over half a century ago.

Without governmental support adjusted to the changes of the territorial frameworks, public transport entrepreneurs should enhance adjustment and anticipation exercises/forecasting demand to collect network-space in a constantly changing territory, either in areas of high population density, or in others where the population claims the right to the transport service, in which it is not always the size of the search that results in revenues for the transport operators. That is to say, if the viability of a range of public transport is complex 
for the IMTT, then the proposal by the transport operator is risky because it is based on an uncertainty of competition and demand.

Then, any effort to defragment the public transport network is currently aggravated due to the banality of the use of private transport (Anable [5], Steg [6]). The modal split, registered mostly in the last two decades of the $20^{\text {th }}$ century, consolidated the loss of share of public transport in favour of the automobile, particularly in interurban spaces where most private companies operate. Between 1991 and 2001, the use of the automobile in the AMP increased from $31 \%$ to $52 \%$, public transport decreased from $42 \%$ to $28 \%$ and foot travel registered a reduction from $27 \%$ to $19 \%$ INE [7]. In 2007, after some years of operation of the Metro of Porto, possibly around one-quarter of passengers were users of private transport, and over $40 \%$ were users of the municipal bus operator (STCP). This trend reveals that the modal imbalance in the AMP only occurs due to the lack of a public transport alternative capable of competing with the advantages exposed by the automobile.

In a country where the expansion of public transport has been consolidated in a fragmented way, responding to the demand imposed by competition and supply-focused strategies, some companies anticipated government requirements to bet on technology to observe the territory behavior, winning greater objectivity in the decision. These companies had the necessary vision to understand that knowledge of the territories' dynamics constituted the basis for a greater decision support and a more assertive intervention on the network, investing in projects and specialized human resources in planning and GIS technologies (Brake et al. [8]). Simultaneously, with the aim of intermodality, in the AMP, a complementary group of companies (ACE) - Intermodal Transport of Porto (TIP) was constituted, which includes road and rail operators, whose most visible actions concern the establishment of a ticketing system and a common tariff (Andante).

Despite recent efforts in the projects developed by several entities who authorize, execute and use the service of public road transport, the difficulty remains of evaluating, and therefore acting on its efficiency and effectiveness. In other words, because it remains impossible to implement governance actions in this domain, the disintegration affects two crucial areas: the operational domain because it remains a logical concession based on supply and competition maintenance with multiplication of companies, and the information domain, because, by placing the emphasis on the supply side, it will enrich even more the network fragmentation while mobility decreases.

\section{The opportunity for integration}

The experience gained in several projects on public transport in the northeast of Portugal (Pacheco $[9,10]$ ) confirms that the difficulty in reversing the imbalance in the use of transport systems resides, obviously, in the sectorization of territorial policies and practices, i.e., in a deficit of governance.

A transport network integrates functioning logics of the territory in constant change, that is to say, its design, performance and success depend on the 
capacity to adjust constantly to those alterations. This ability to adjust is a result of the modus operandi of the governmental policies as well as the governance oriented to the development.

The increasing difficulty to observe and manage different geographical scales of the demand in a transport network is commonly known. This difficulty is related to the complexity of the movements undertaken by a population that define lines of desire for mobility that are not very clear in space and time. In fact, the linearity of commuting, associated with the expansion of cities of the past, appears now dimmed by a wide range of destinations that each develops for his/her everyday life, largely caused by the speed of the transformation and specialization of land use (Melia et al. [11]). Nowadays, a journey is rarely constituted by a single trip and, either it includes long miles, or it is shared by various paths of very short distance (Banister [12]).

Recognizing the need to implement mechanisms of vision and integrated analysis, the Ministry of Public Works, Transport and Communication established in the Normative Ordinance 32/2009 [2] the following: "[the] operators of public road passenger transport who operate under the RTA should provide to the IMTT, I.P, and to the territorially competent AMT, in the case of full exercise of their functions, data on careers that are actually in operation, through the informatics' support or via online D. 37982 [13]. This Order, among other aspects, is a fundamental contribution to the regulation of competition and the knowledge of the network of road passenger transport by the competent authorities. Until now, much of the support of territorial analysis (cartographic), available for the decision, is still analog. In this context, and given the technical availability afforded by the development of technologies in a GIS environment, the opportunity now emerges to generalize the collection, treatment and monitoring of information concerning the network(s) of transport in a more accurate way, resulting in important procedures to support the decision by the central administration and transport operators.

However, if for some this is more an exercise demanding the use of new technologies of storage and processing network, for most, this is a new requirement that has forced the recruitment of a specialized labor force to lift and carry a set of data contained on a platform where there is information that clearly should be fed by various public entities. In fact, from the four groups of information needed to respond to the Normative Ordinance 32/2009 [2] (table 1), only one should be fully completed by the transport operators ("Vehicle"). The remaining information is another entities' responsibility.

The new mobility dynamics require new ways of transport networks operating and planning. The challenges facing today's road passenger transport are essentially, more demanding given the range of existing alternatives and advantages of individual modes. The need to promote a readjustment in the modal split, in order to develop more sustainable mobility patterns, requires greater investment on the part of the transport operators when it comes to the planning component based on knowledge of the territory. Here, the GIS technologies appear as essential elements to pursue these goals (Keshkamat et al. [14]) and this platform aims to promote this new way of looking at operations, 
Table 1: Required data by the transport operators through the platform of the Normative Ordinance nr. 32/2009 [2].

\begin{tabular}{|c|c|c|}
\hline Group & $\begin{array}{l}\text { Required information by the } \\
\text { transporters }\end{array}$ & $\begin{array}{l}\text { Entity } \\
\text { responsible of } \\
\text { the Information }\end{array}$ \\
\hline \multirow{2}{*}{ Route } & $\begin{array}{l}\text { Code; charter code; name; origin; } \\
\text { destination medium course }\end{array}$ & IMTT \\
\hline & $\begin{array}{c}\text { Type of collection; validation and type } \\
\text { of titles; Transported passengers. }\end{array}$ & Operators \\
\hline Vehicle & $\begin{array}{l}\text { Type of vehicle; help systems; } \\
\text { nourishment; Acclimatization; lowered } \\
\text { floor; special accessibility; Rush hour } \\
\text { number; medium stocking. }\end{array}$ & Operators \\
\hline Stop & $\begin{array}{l}\text { Location; street; designation; code; } \\
\text { information; Available to the public; } \\
\text { restrictions; given equipment; State of } \\
\text { conservation; general characterization. }\end{array}$ & Municipalities \\
\hline Infrastructure & $\begin{array}{l}\text { One-way; number of pathways per way; } \\
\text { Bus corridor; type of pavement; } \\
\text { Maximum, medium and minimum route } \\
\text { time }\end{array}$ & $\begin{array}{l}\text { Municipalities } \\
\text { and/or } \\
\text { Estradas de } \\
\text { Portugal } \\
\end{array}$ \\
\hline
\end{tabular}

either by those planning the transport system and its different networks, or by the transport operator. Nevertheless, for the latter, it is a very penalizing task as it not only obliges him to do surveys, downloads and information updates on the responsibility of other public entities, but he is also deprived of the necessary reading concerning the territories' dynamics for its planning activities and network management. In other words, if it is true that governmental initiatives pass through the incorporation of information on a territorial basis, as described recently in the public presentation of the first phase of the project (Seabra [15]), then the inefficiency of previous technical mechanisms on the part of the Portuguese government cannot be ignored - the task imposed by Normative Ordinance 32/2009 [2] required, on the part of the transport operators, an investment on the fieldwork, georeferencing and loading information already existing in other institutions.

\section{Territorial information - the basis for the integration of the transport networks}

The conception of an integrated and flexible transport system must begin to address the territories' dynamics, that is, where, how, when and why does it generate pressure on the search for collective transport. This previous assessment can only happen when the multiple entities involved in the planning and 
territorial intervention are connected to one single database in a GIS environment. Autarkic, security, statistics, and transport institutions, among others, collective and individual, should contribute to feed a common database useful for all.

Regarding the desired integration of the transport networks and the integrated solutions in the territorial intervention, you could add more value to the construction of the current database if, beyond the required data rightly divided by the responsible entities as shown in the previous Table, you could incorporate other equally pertinent data like the size of the population, housing, family income, dominant age groups, motorization rates, modal distribution, the daily mobility of the population, the main equipment that generate demand (schools, health units, commercial areas, service areas, financial areas, etc), parking lots, great transport interfaces, terrain inclines, significant elements to security questions, proximity to road axis of great capacity, interface operation: Schedule articulation. These levels of analysis show up as an intention by the Portuguese government after the information carrying phase regarding the collective transport networks is completed, as can be seen in the results shown in Figure 1.

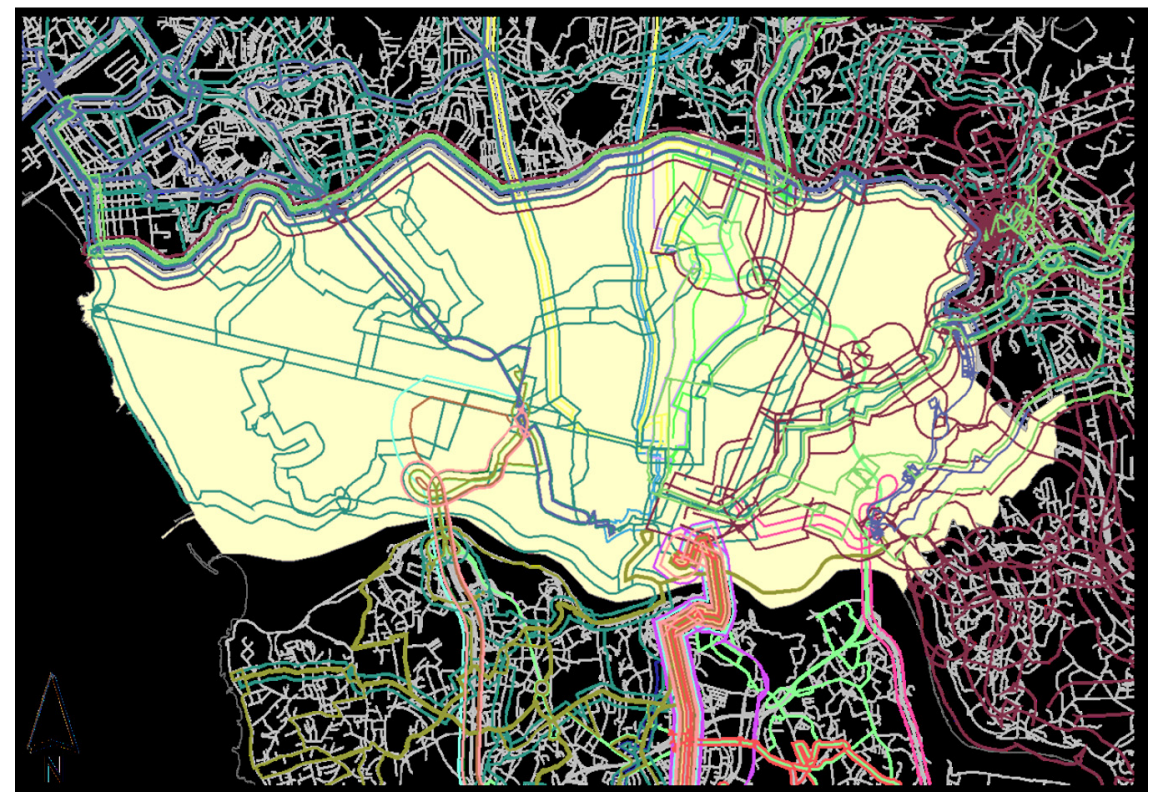

Figure 1: An initial view of the information carried by the operators on the central area of (AMPorto) (Seabra [15]).

Looking at this, it is evident that the great results of the work done by the IMTT with the intensive cooperation of the transport operators, at a time where there are intentions to load in this base data regarding the territories' dynamics. Additionally, as shown in figure 2, and having our decade-long experience as a starting point, the adjustment of the collective transport network to the needs of 
the movements of the population can only be anchored in its raison d'etre people, activities, habits and ways of life. From the picture represented, that zooms in on a parish of AM - Senhora da Hora, in the municipality of Matosinhos (north of the city of Oporto), we can see the existence of a collective transport network characterized by the inertia of the tracings, better adjusted to the history of the service and not so much to the emergencies of new transport solicitations.

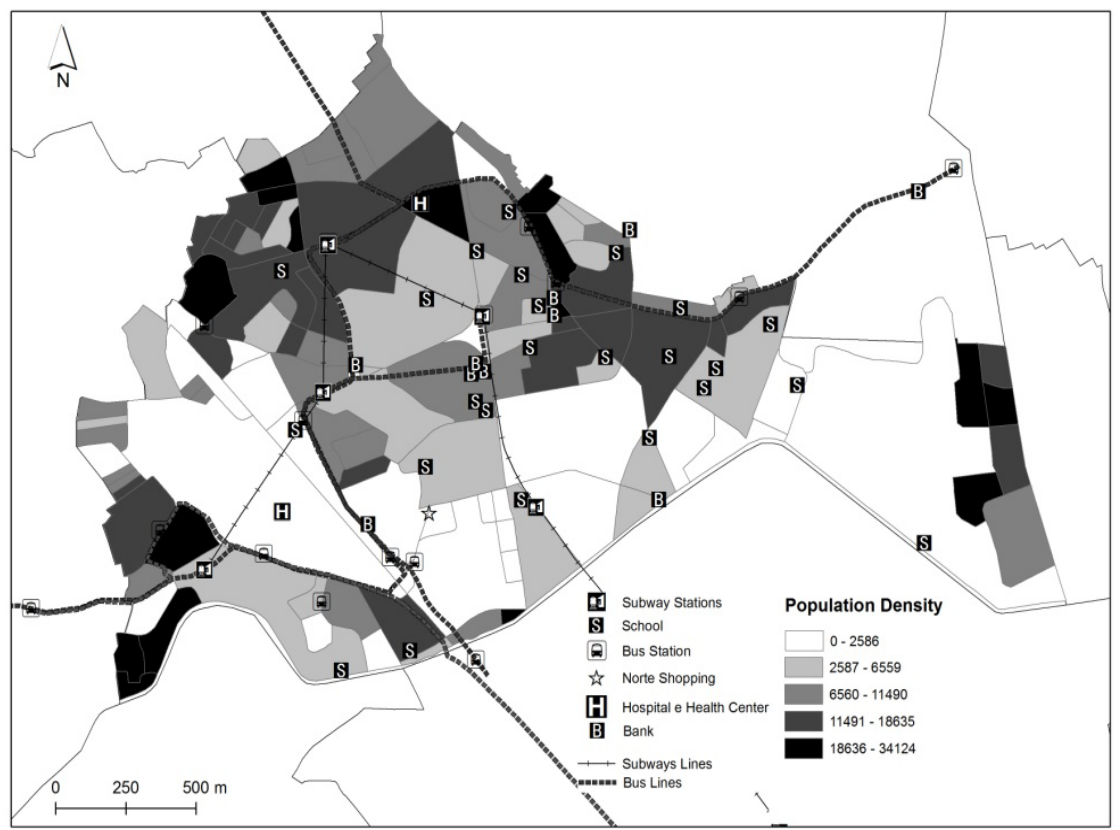

Figure 2: Network observation in a territorial base - examples of indicators for Senhora da Hora.

While you could lengthen our indicator list and the real case tests/test studies even more, what is sure is that from our point of view, these are some of the crucial elements in order that a collective road transport operator can plan and intervene in a more realistic fashion on his network. Additionally, in this way, we hope to develop a service that will be closer to the real needs of the territories, more competitive on the context of the other modes and more consentaneous with the principles of a more sustainable mobility.

\section{Conclusion}

The development of survey and treatment of geographical information technologies in the last decade has allowed for significant advances regarding the domain of knowledge of the collective transport networks, with a special 
highlight to the survey and systematization of data, with the final objective being a better objectivity in the analysis, prediction, and management of the suitability of the data and performance on the territories they operate. Any information system built in regards to the collective transport networks must have a strong concern with the issues not just of the systematization of the processes and the consultation of information, but must also have components that provide an improvement of the capacity of planning and information analysis from the central management organs, the transport operators and the users.

The collective road transport sector needs clear modernization in order to stake a claim as an alternative to the individual transport and initiatives that seek to consolidate; that need should be welcomed as a positive element in the process. They must be, however, elements that beyond strengthening the central administration, have as a main concern to grant autonomy and to supply tools of strategic management to the transport operators.

The carrying of information imposed by the Normative Ordinance 32/2009 should happen after the construction of a common platform that integrates data from several entities that could build the necessary thickness to territorial readings, in which we would place the network and its topological elements, performance elements and development elements. In this way, the supplementary effort by the transport operators would have been avoided; we would have won ground in the domain of the concert of institutional interests on the processes of decision-making and planning; we would have taken advantage of the opportunity to introduce quality and governing assertiveness to the integration of transport networks; in conclusion, we would have given a secure step to the desired mobility to orient the development and territories' sustainability.

It is necessary to articulate competences and responsibilities, so afterwards, we can articulate interests. The reasons for the disintegration of the transport networks are found in the new processes and territory dynamics, which are important to understand and monitor so that we can define the processes of work and intervention that are the result of a convergence of interests.

\section{References}

[1] DGOTDU. Programa Nacional da Política de Ordenamento de Território. Programa de Aç̧ão. Lisboa: Assembleia da República, pp. 39, 77, 882007.

[2] Normative Ordinance nr. 32/2009 of 17th September.

[3] PACHECO, E. Transportes Colectivos Rodoviários no Grande Porto. Ensaio de Geografia Humana, Faculdade de Letras da Universidade de Coimbra: Coimbra.

[4] Decree 37272/ 1948 of 31st December.

[5] Anable, J., Complacent car addicts or aspiring environmentalist? Identifying travel behaviour segments using attitude theory. Transport Policy, 12(1), pp. 65-78, 2005.

[6] Steg, L., Car use: lust and must. Instrumental, symbolic and affective motives for car use. Transportation Research Part A: Policy and Practice, 39(2-3), pp.147-162, 2005. 
[7] INE, Movimentos Pendulares na área metropolitana do Porto 1991-2001, deslocações entre o local de residência e o local de trabalholestudo, Instituto Nacional de Estatística: Lisboa, 2003.

[8] Brake, J., Nelson, J.D. \& Wright, S., Demand responsive transport: towards the emergence of new market segment. Journal of Transport Geography, 12(4), pp. 323-327, 2004.

[9] PACHECO, E., Estudo da Rede dos Transportes Colectivos do Vale do Ave, Associação de Municípios do Vale do Ave: Guimarães, 2001.

[10] PACHECO, E., Análise e experimentação de novos dispositivos de mobilidade urbana - TUG, Acção C - Promoção do transporte público, PAGUS, INTERREG IIIC, Nord Est SUD Ouest, 2007.

[11] Melia, S., Parkhurst. \& Barton, H., The paradox of intensification. Transport Policy, 18(1), pp. 46-52, 2011.

[12] Banister, D., The sustainable mobility paradigm. Transport Policy, 15(3), pp.73-80, 2008.

[13] Decree $n^{\circ} 37982 / 2009$ of $10^{\text {th }}$ September.

[14] Keshkamat, S., Looijen, J., Zuidgeest, M., The formulation and evaluation of transport route planning alternatives: a spatial decision support system for the Via Baltica Project, Poland. Journal of Transport Geography, 17(1), pp. 54-64.

[15] Seabra, I. Communication, 11 May 2011, Sistema de Informação geográfica de Carreiras. Instituto da Mobilidade e dos Transportes Terrestre, Lisboa. 